\title{
Economic evaluation of intravenous iron treatments in the management of anemia patients in Greece
}

This article was published in the following Dove Press journal:

ClinicoEconomics and Outcomes Research

3 May 2012

Number of times this article has been viewed

\author{
Vassilis Fragoulakis' \\ Georgia Kourlaba' \\ Dimitris Goumenos ${ }^{2}$ \\ Manousos Konstantoulakis ${ }^{3}$ \\ Nikolaos Maniadakis' \\ 'Department of Health Services \\ Management, National School of \\ Public Health, Athens, ${ }^{2}$ Department \\ of Medicine University Hospital \\ of Patras, Patras, ${ }^{3}$ Department of \\ Medicine, Athens Medical School, \\ Athens, Greece
}

Purpose: To conduct an economic evaluation comparing Ferinject ${ }^{\circledR}$ (ferric carboxymaltose [FCM]) with Venofer ${ }^{\circledR}$ (iron sucrose [IS]) and CosmoFer ${ }^{\circledR}$ (low-molecular-weight iron dextran [LMWID]) in the management of iron deficiency anemia in Greece.

Patients and methods: A cost-minimization analysis was conducted since there are no clear data indicating that one of these regimens is superior to the others in terms of efficacy. Main data inputs were based on bibliography and validated by clinicians. The economic evaluation was conducted for inpatients (ie, surgical patients or patients hospitalized due to a disease related to chronic or acute blood loss) and outpatients (eg, nondialysis chronic kidney disease patients), separately. Analysis was carried out from a National Health Service (NHS) perspective and also from a patient perspective. Total cost treatment reflects the cost of drugs, the cost of all resources expended in patient management such as the cost of disposables for each infusion, the monitoring costs during infusion (salaries of personnel), other hospital expenses, the cost for management of adverse events, the productivity loss, and the traveling cost for patients.

Results: In the case of outpatients, the mean total cost per patient in the FCM arm was $€ 198.6$, in the IS arm €627.7, and in the LMWID arm, €510.5. For inpatients the mean total cost was estimated at $€ 189.2$ for FCM while it was $€ 419.9$ and $€ 228.8$ for IS and LMWID, respectively. Budget impact analysis for a typical Greek hospital with 100 patients revealed that the total cost of FCM (inpatients analysis) was $113 \%$ and $15.4 \%$ lower against their comparators. In an outpatient situation, the total cost of FCM was $201.1 \%$ and $151.8 \%$ lower compared with IS and LMWID, respectively.

Conclusion: Ferric carboxymaltose may represent a cost-saving option compared with the most likely alternative existing therapies used for the management of anemia in the National Health Service of Greece.

Keywords: economic evaluation, cost minimization, ferric carboxymaltose, anemia, iron therapy

\section{Introduction}

Iron deficiency anemia (IDA) is a common and widespread disorder for adult men and women of different age bands, races, and ethnic groups. ${ }^{1}$ It has been estimated that in developed countries it occurs in $2 \%-5 \%$ of adult men and postmenopausal women and it represents a common cause of referral to gastroenterologists. ${ }^{2}$ The prevalence of IDA has been associated with conditions which cause chronic blood loss, such as inflammatory bowel disease, heavy uterine bleeding in postpartum women, and in chronic kidney disease. ${ }^{3-8}$ Its symptoms include fatigue, headache, dizziness, breathlessness, palpitations, and reduced cognitive function. ${ }^{7,8}$ In this context it can reduce patient
Correspondence: N Maniadakis Department of Health Services and Management, National School of Public Health, Alexandras Av,

196, Athens II52I Greece

Tel +302106467097

$\mathrm{Fax}+302132010194$

Email nmaniadakis@esdy.edu.gr 
physical performance, ability to work, health-related quality of life (HR-QOL), and it may increase morbidity and mortality. ${ }^{7,8}$

Blood transfusion can elevate hemoglobin concentration in the short term, however it does nothing to address the underlying disorder and therefore despite its use there is still an unmet need. Moreover, in Greece and other countries there are often insufficient quantities to cover existing blood transfusion needs. In addition, blood donation is not free of risks, as it is often associated with infections and medical errors. Finally, this treatment is relatively expensive as the collection, storage, and use of blood comes at a cost. ${ }^{9,10}$

Thus, because of its convenience, availability and relative lower cost, oral iron represents a viable alternative treatment for anemia patients. Nonetheless, this treatment option too has some shortcomings and for this reason patients may also benefit from intravenous iron therapy. Specifically, ferric carboxymaltose (FCM; Ferinject ${ }^{\mathbb{}}$; Vifor Pharma, Wigan, UK), iron sucrose (IS; Venofer ${ }^{\circledR}$; Vifor International Inc, Zurich, Switzerland) and low-molecular-weight iron dextran (LMWID; CosmoFer ${ }^{\circledR}$; Pharmacosmos, Holbaek, Denmark) are commonly used intravenous (IV) iron therapies worldwide. ${ }^{11}$ The safety and efficacy, in terms of hemoglobin increase, of these agents is well documented in the literature and all three have been proven and deemed to be clinically equivalent. ${ }^{12-18}$ Nonetheless, they do not have the same mode of delivery and resource implications, and they also differ in terms of their price. Given that health care resources are scarce and must be spent wisely, a cost minimization analysis was undertaken to assess the above therapeutic alternatives in terms of their total treatment cost for the standard therapeutic course of $1000 \mathrm{mg}$ in the Greek setting. ${ }^{19}$ The present paper presents the results of this economic analysis. This is particularly important at present. In the context of the financial crisis and the accompanying fiscal pressures, the memorandum signed with the International Monetary Fund, European Central Bank, and European Commission provides that pharmaceutical expenditure must be cut by $50 \%$ within a period of three years and total public health care expenditure must be maintained below $6 \%$ of GDP. Also patients are facing higher unemployment rates and lower income. Thus, an economic analysis may help to find ways to improve the economics of health care and assist patients.

\section{Material and methods}

\section{Type and perspective of evaluation}

Because treatments are equivalent in terms of effectiveness, a cost minimization analysis was undertaken. Thus only the total therapy cost of different options was evaluated. Because iron can be administered either in an inpatient setting (ie, surgical patients or patients hospitalized due to a disease related to chronic or acute blood loss) or in an outpatient setting (eg, nondialysis chronic kidney disease patients), the economic evaluation was conducted for these two large categories of patients, separately. The analysis was carried out from the perspective of the National Health Service (NHS) and also of patients. In the NHS perspective, health care costs associated directly with the medical care of patients were considered and they reflect the outpatient and inpatient management of patients respectively. From the patient perspective, transportation costs and productivity losses were accounted for.

\section{Costing methodology}

The total cost related to each treatment reflects the cost of drugs, the cost of disposables utilized in drug delivery, the monitoring cost of infusion, other hospital-related expenses, the management of adverse events, patient productivity loss, and patient traveling cost (Tables 1 and 2). Specifically, total drug cost is calculated as the product of total dose of $1000 \mathrm{mg}$ (two units) and the drug price per unit. The prices of drugs used in the model are set in the last price bulletin issued by the Ministry of Commerce and are common across all public hospitals in Greece. ${ }^{20}$ Data regarding the disposables used for drug administration were based on expert advice. In particular, it was assumed that a serum device and a cannula were used per patient for each hospital visit. Furthermore, for inpatients, it was assumed that the average length of stay was 1 week. Thus, in the case of inpatient management, two additional visits for IS and none for LMWID and FCM were

Table I Costing methodology used in the model

\begin{tabular}{ll}
\hline Parameter & Direct cost computation \\
\hline Total cost of drugs & Number of units $\times$ cost per unit \\
Total cost of & (Units of disposable per infusion $\times$ unit cost $) \times$ \\
disposables & number of visits \\
Total monitoring cost & (Gross salary of doctor per month/ \\
True hospital cost & 25 days $/ 480$ minutes $/$ day + gross salary of \\
& nurse per month $/ 25$ days $/ 480$ minutes $/$ day) $\times$ \\
minutes of infusion $\times$ number of infusions \\
$($ Total infusion hours $/ 8$ hours $) \times$ hospital \\
cost $\times$ number of visits \\
Indirect cost computation \\
Total productivity loss & Number of visits $\times($ Gross domestic product \\
& per capita/300) \\
Total traveling cost & Number of visits $\times$ traveling cost per visit \\
\hline
\end{tabular}

Notes: Disposable: cannula and serum device. In the case of inpatients, as "number of visits", we have used the number of additional visits for infusion after patient discharge. 
Table 2 Cost per item used in the model

\begin{tabular}{|c|c|c|c|}
\hline \multirow[t]{2}{*}{ Cost of drugs* } & \multirow[t]{2}{*}{ Cost $(€)$ per unit } & \multicolumn{2}{|c|}{ Total number of units } \\
\hline & & Inpatients & Outpatients \\
\hline Cosmofer (5 amp $\times 100 \mathrm{mg})$ & 28.48 & 2 & 2 \\
\hline Venofer (5 amp $\times 100$ mg) & 31.64 & 2 & 2 \\
\hline Ferinject $(5 \mathrm{amp} \times 100 \mathrm{mg})$ & 85.93 & 2 & 2 \\
\hline Cost for personnel time & Cost $(€)$ per hour** & Needed hours & Needed hours \\
\hline Doctor/nurse & $€ I I .50 / € 6.50$ & & \\
\hline Cosmofer & & 8 & 8 \\
\hline Venofer & & 10 & 10 \\
\hline Ferinject & & 0.25 & 0.25 \\
\hline Number of additional visits & Cost $(€)$ per visit** & & \\
\hline Cosmofer & 280.00 & 0 & 1 \\
\hline Venofer & 280.00 & 2 & 5 \\
\hline Ferinject & 280.00 & 0 & 1 \\
\hline Disposables per visit & Cost $(€)$ per unit & Units per infusion & Units per infusion \\
\hline Serum device & 0.36 & I & 1 \\
\hline Cannula & 0.40 & I & $\mathrm{I}$ \\
\hline
\end{tabular}

Notes: *Price Bulletin; **National School of Public Health.

assumed. In the case of outpatient management, five visits for IS and one for LMWID and FCM were assumed. In both options, the number of required visits per patient was based on expert advice combined with local average length of stay data to reflect the local management of anemia.

Monitoring cost reflects the time spent by staff to look after patients during administration and is based upon the salary per minute and the minutes expended by staff members to monitor infusions, and the number of corresponding visits. It must be noted that patients must be kept under close medical observation during the period of infusion. Regardless, personnel costs must be attributed to those treated in the hospital according to the time spent. This is also an opportunity cost. Hence, in the model it has been assumed that a doctor and a nurse should monitor patients during the IV infusion, according to local experts and summary of product characteristics (SPC).

Data concerning the time to infusion were collected from the $\mathrm{SPCS}^{21-23}$ and were verified by local experts. Based on expert opinion, the average time spent on LMWID infusion was set at 8 hours in total, even though it is acknowledged that in some settings $1000 \mathrm{mg}$ can be given over 5 hours. ${ }^{24}$ For similar reasons, for IS the total amount of care (preparation, infusion, post-therapy monitoring) is set at 10 hours.

The hospital cost quantifies the remaining operating and overhead cost for accommodating a patient during the infusion. Thus, this type of cost is linearly related to the time spent for the infusion. Based on data gathered by the National School of Public Health on behalf the Ministry of Health across the country, the hospital operating and overhead cost (excluding personnel and drugs) was estimated at $€ 280$ for a normal morning hospital shift, on average.
The management of adverse events reflects expenses for the treatment of headache, dizziness, constipation, nausea, vomiting, diarrhea, abdominal pain, injection site reactions, fatigue, pyrexia, chest pain, rash, muscle cramp, back pain, dyspnea, and cough, which are commonly reported adverse events and are similar amongst comparators. ${ }^{25}$ Productivity loss reflects the foregone production due to missed days of work in order to receive the treatment or due to anaphylactic reactions in patients receiving LMWID. It may be an underestimate as in some cases patients may be accompanied by family members and thus productivity loss is higher. It must be noted that hospitalized patients are not incurring any productivity loss in our analysis. Furthermore it is assumed that in the case of IS a day of work is lost due to travelling, treatment delivery, posttreatment monitoring, and hospital administration and waiting time.

This indirect cost per day is calculated in terms of the gross domestic product per capita divided by the number of working days per year. ${ }^{26}$ In the case of LMWID, it was assumed that delayed anaphylactic reactions impose 2 days absence of work for recovery without hospitalization in the case of $15 \%$ of patients. ${ }^{27,28}$

Traveling cost reflects the expenses of patients for traveling to and from the hospital. In Greece almost all patients reach hospitals for IV infusion by using public or private transport facilities. The mean cost per visit was obtained from the literature, where the mean traveling cost per patient visit has been estimated at $€ 40 .{ }^{29}$ In a similar manner, the total traveling cost is calculated by multiplying the travel cost for each visit by the number of visits. 


\section{Uncertainty}

To deal with uncertainty, probability distributions were specified around all of the main analysis parameters. Specifically, probabilistic variables for the time infusion, transportation cost and productivity loss were associated with normal distributions around the mean and a 10\% coefficient of variation (CV). Bias-corrected uncertainty intervals (UI) of costs have been calculated using the percentile method of nonparametric bootstrapping (using 1000 replications). ${ }^{30}$ It is important to indicate that, given the probabilistic nature of all components, the cost of each comparator can be slightly different in each bootstrap experiment. Nonetheless, the bootstrapped costs follow a normal distribution based on the central limit theorem. ${ }^{31}$ In addition a supplementary one-way sensitivity analysis was conducted. Hence, the cost of drugs and the main cost components were varied at $\pm 20 \%$ to examine the stability of results under different assumptions.

\section{Budget impact}

A supplementary budget impact analysis was conducted in order to estimate the budget impact of specific utilization scenarios. As mentioned in the introduction, this is important as drug and health care budgets must be reduced over time. The objective was to assess the economic impact within a 1-year time horizon. Hence, the results presented below refer to the total cost of 12 months' use of each therapy for a hypothetical cohort of 100 patients. It is straightforward to compute the economic benefit (loss) from a decision to use different therapies.

\section{Results}

Results are shown in Table 3. In particular, in the outpatient setting the direct therapy cost per patient in the FCM arm was $€ 198.6$ (95\% UI: $€ 194.3-€ 204.2$ ), in the IS arm was $€ 627.7$ (95\% UI: €587.9-€675.8), while in the LMWID arm was $€ 510.5$ (95\% UI: $€ 465.4-€ 560.5)$. Thus, the direct cost in the FCM group was the lowest, with a mean difference of $€ 429.1$ (95\% UI: $€ 390.1-€ 477.8$ ) and $€ 311.9$ (95\% UI: €268.7-€359.2) in relation to IS and LMWID, respectively.

The mean traveling cost for patients in FCM was $€ 40.4$ (95\% UI: €33.9-€48.1) against €202 (95\% UI: €169.6-€240.7) and $€ 40.4$ (95\% UI: €33.9-€48.1) for IS and LMWID, respectively. The productivity loss was estimated at $€ 73.3$ (95\% UI: $€ 39.7-€ 128.2$ ) in the case of FCM, while it was $€ 366.7$ (95\% UI: $€ 212.5-€ 580.2$ ) in the case of IS and $€ 96$ (95\% UI: €65.2-€138.7) for LMWID. The main item driving the direct cost in the FCM arm was the cost of medication

Table 3 Total cost and cost components per treatment arm

\begin{tabular}{|c|c|c|c|}
\hline Mean (95\% LUI-95\% UUI) & FCM & IS & LMWID \\
\hline \multicolumn{4}{|l|}{ Outpatient } \\
\hline \multicolumn{4}{|l|}{ Direct cost $(€)$} \\
\hline Drugs & $17 \mid .9(\mathrm{n} / \mathrm{a})$ & $63.3(\mathrm{n} / \mathrm{a})$ & $57(\mathrm{n} / \mathrm{a})$ \\
\hline Adverse events & $12.4(8.4-18)$ & $12.4(8.4-18)$ & $12.4(8.4-18)$ \\
\hline Disposables & $0.8(0.5-1.1)$ & $3.8(3.5-4.1)$ & $0.8(0.5-1.1)$ \\
\hline Monitoring & $4.8(3.8-6)$ & $197.7(\mid 76-219.6)$ & $159.9(125.1-196)$ \\
\hline Hospital cost & $8.8(7.9-9.8)$ & $350.5(315.1-392.6)$ & $280.4(252 .|-3| 4 . \mid)$ \\
\hline Total direct cost & $198.6(194.3-204.2)$ & $627.7(587.9-675.8)$ & $510.5(465.4-560.5)$ \\
\hline \multicolumn{4}{|l|}{ Other costs $(€)$} \\
\hline Productivity loss & $73.3(39.7-128.2)$ & $366.7(2 \mid 2.5-580.2)$ & $96(65.2-138.7)$ \\
\hline Traveling cost & $40.4(33.9-48.1)$ & $202(169.6-240.7)$ & $40.4(33.9-48.1)$ \\
\hline Total other costs & II $3.7(73.6-176.3)$ & $568.7(382-820.9)$ & | 36.4 (99.1-186.9) \\
\hline \multicolumn{4}{|l|}{ Inpatient } \\
\hline \multicolumn{4}{|l|}{ Direct cost $(€)$} \\
\hline Drugs & $17 \mid .9(\mathrm{n} / \mathrm{a})$ & $63.3(\mathrm{n} / \mathrm{a})$ & $57(\mathrm{n} / \mathrm{a})$ \\
\hline Adverse events & $12.5(8.7-17.7)$ & $12.5(8.7-17.7)$ & $12.5(8.7-17.7)$ \\
\hline Disposables & $0(\mathrm{n} / \mathrm{a})$ & $1.5(1.2-1.8)$ & $0(n / a)$ \\
\hline Monitoring & $4.8(3.8-5.9)$ & 197.5 (I77.3-220.4) & $159.3(126-195.6)$ \\
\hline Hospital cost & 0 (n/a) & 140 (I25.9-|56.I) & $0(\mathrm{n} / \mathrm{a})$ \\
\hline Total direct cost & I89.2 (|85.|-|94.4) & $4 \mid 4.9(388.7-442.7)$ & $228.8(194 . \mid-265.2)$ \\
\hline \multicolumn{4}{|l|}{ Other costs $(€)$} \\
\hline Productivity loss & $0(n / a)$ & I 44.5 (86.3-225.7) & 22.7 (I7.7-28) \\
\hline Traveling cost & $0(n / a)$ & $80.1(66.6-95.6)$ & $0(n / a)$ \\
\hline Total other costs & $0(\mathrm{n} / \mathrm{a})$ & $224.7(152.9-321.3)$ & 22.7 (I 7.7-28) \\
\hline
\end{tabular}

Notes: Based on 1000 bootstrap replications.

Abbreviations: LUI, lower uncertainty interval; UUI, upper uncertainty interval; FCM, ferric carboxymaltose; IS, iron sucrose; LMWID, low-molecular-weight iron dextran. 
(86.5\%), while the monitoring cost and the hospital operating and overhead cost was substantially lower compared to other agents due to the different delivery mode. These figures are important as average monthly income for many workers has fallen by around $€ 500$ to $€ 700$ as a result of the financial crisis.

For inpatients, the mean direct cost of therapy in the FCM arm was $€ 189.2$ (95\% UI: $€ 185.1-€ 194.4)$, in the IS arm it was $€ 414.9$ (95\% UI: €388.7-€442.7), while in the LMWID arm it was €228.8 (95\% UI: €194.1-€265.2). As with the previous findings, the mean total treatment cost in the FCM group was the lowest, with a mean reduction of $€ 225.7$ (95\% UI: $€ 200.2-€ 252.2$ ) and $€ 39.6$ (95\% UI: €6.6-€75.7) relative to IS and LMWID, respectively. FCM is characterized by an absence of productivity loss or traveling cost in this scenario. By contrast, in the case of IS, productivity loss was estimated at $€ 144.5$ (95\% UI: €86.3-€225.7), while it was €22.7 (95\% UI: $€ 17.7-€ 28.0)$ in the case of LMWID. The traveling cost was estimated at $€ 80.1$ (95\% UI: €66.6-€95.6) in the case of IS.

\section{Budget impact}

Budget impact analysis takes into account the budget implications for hospitals. Despite the fact that FCM has a higher price compared to the other treatments it is the least costly option to use (Figure 1). Overall, per annum the treatment of 100 patients on an outpatient basis amounts to $€ 19,787$, against $€ 61,358$ and $€ 49,822$ for IS and LMWID respectively, delivering corresponding savings of up to $210 \%$ and $152 \%$ respectively. Similarly, overall per annum, treatment of 100 patients on an inpatient basis totals $€ 18,836$, against $€ 40,130$ and $€ 21,746$ for IS and LMWID respectively, delivering corresponding savings of $113 \%$ and $15 \%$.

\section{Sensitivity analysis}

Results from a one-way sensitivity analysis are presented in Table 4, where the main input parameters of the model such as the cost of drugs, the gross salaries of personnel and the number of visits are altered within a $\pm 20 \%$ range. This analysis indicates that FCM remains an attractive option relative to other therapies in the majority of sensitivity analyses. The results are highly sensitive only to the cost of drugs, which however are deterministic. It must be noted that deterministic results are slightly different from the mean bootstrap results due to correction bias term incorporated in the probabilistic analysis.

\section{Discussion}

Anemia is a fairly common condition, affecting both men and women of all ages, races and ethnic groups. Anemia is frequently caused by iron deficiency, which is associated with a variety of coexisting conditions. Patients with anemia may benefit from iron therapy. Although oral iron is the treatment of choice for the majority of the patients because of its effectiveness, safety, and cost, oral iron has disadvantages, including poor compliance, high incidence of adverse gastrointestinal effects and high potential for interactions with other treatments. Therefore, parenteral administration of iron (ie, intravenous iron) has been introduced in clinical practice. FMC, IS, and LMWID are the main available intravenous IV iron forms, in Greece and elsewhere.

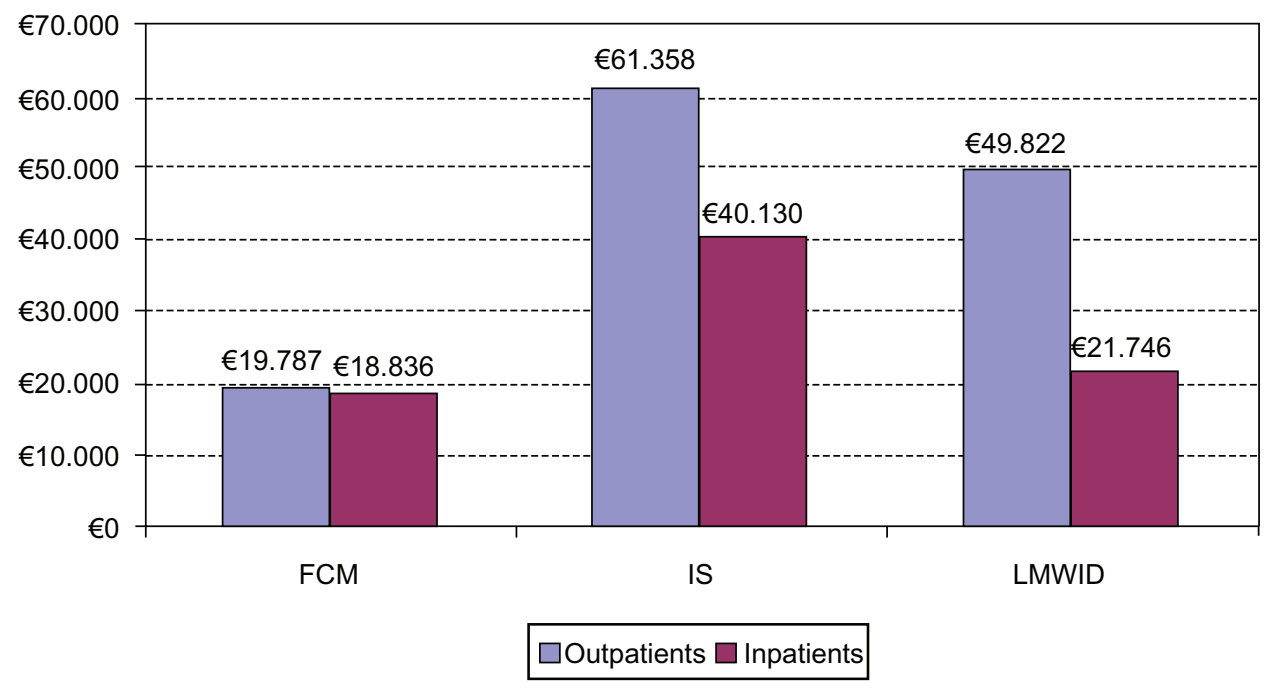

Figure I Budget impact analysis per year for a cohort of 100 patients.*

Note: *Assuming $100 \%$ substitution rate amongst comparators.

Abbreviations: FCM, ferric carboxymaltose; IS, iron sucrose; LMWID, low-molecular-weight iron dextran. 
Table 4 Total cost per treatment arm* based on one-way sensitivity analysis for the main model parameters

\begin{tabular}{|c|c|c|c|c|c|c|c|c|}
\hline & \multirow[t]{2}{*}{$-20 \%$} & \multirow[t]{2}{*}{$20 \%$} & \multicolumn{3}{|l|}{$(-20 \%)$} & \multicolumn{3}{|l|}{$(+20 \%)$} \\
\hline & & & FMC & IS & LMWID & FMC & IS & LMWID \\
\hline \multicolumn{9}{|l|}{ Inpatients } \\
\hline Cost per drug unit for FMC & 68.7 & 103.1 & $€ I 54.0$ & $€ 40 \mathrm{I} .3$ & $€ 217.0$ & $€ 222.7$ & $€ 40 \mathrm{I} .3$ & $€ 217.5$ \\
\hline Gross salary per month (Doctor) & $\mathrm{I}, 840.0$ & $2,760.0$ & $€ \mid 87.8$ & $€ 377.7$ & $€ 198.5$ & $€ 188.9$ & $€ 424.9$ & $€ 236.4$ \\
\hline Gross salary per month (Nurse) & $\mathrm{I}, 040.0$ & $1,560.0$ & $€ \mid 88.0$ & $€ 388.0$ & $€ 206.8$ & $€ \mid 88.7$ & $€ 4 \mid 4.6$ & $€ 228.2$ \\
\hline Additional visits (for IS) & 1 & 3 & $€ \mid 88.4$ & $€ 330.5$ & $€ 217.5$ & $€ \mid 88.4$ & $€ 472.0$ & $€ 217.5$ \\
\hline Cost per visit & 224.0 & 336.0 & $€ \mid 88.4$ & $€ 401.3$ & $€ 217.5$ & $€ 188.4$ & $€ 401.3$ & $€ 217.5$ \\
\hline \multicolumn{9}{|l|}{ Outpatients } \\
\hline Cost per drug unit for FMC & 68.7 & 103.1 & $€ 163.5$ & $€ 6 \mid 3.6$ & $€ 498.2$ & $€ 232.3$ & $€ 6 \mid 3.6$ & $€ 498.2$ \\
\hline Gross salary per month (Doctor) & $\mathrm{I}, 840$ & 2,760 & $€ 197.3$ & $€ 519.3$ & $€ 479.3$ & $€ 198.5$ & $€ 566.4$ & $€ 517.2$ \\
\hline Gross salary per month (Nurse) & 1,040 & $\mathrm{I}, 560$ & $€ 197.5$ & $€ 529.5$ & $€ 487.5$ & $€ 198.2$ & $€ 556.2$ & $€ 509.0$ \\
\hline Additional visits (for IS) & 4 & 6 & $€ 197.9$ & $€ 542.8$ & $€ 498.2$ & $€ 197.9$ & $€ 684.3$ & $€ 498.2$ \\
\hline Cost per visit & 224.0 & 336.0 & $€ 196.1$ & $€ 6 \mid 3.6$ & $€ 442.2$ & $€ 199.6$ & $€ 6 \mid 3.6$ & $€ 554.2$ \\
\hline
\end{tabular}

Note: *Only direct cost was considered.

Abbreviations: FCM, ferric carboxymaltose; IS, iron sucrose; LMWID, low-molecular-weight iron dextran.

In the present study, a comparison of the cost among FMC, IS and LMWID, was undertaken using a probabilistic model. The comparison was conducted on an inpatient and outpatient basis from an NHS and patient perspective in Greece. According to the results, FMC may represent a cost-saving option, as it is associated with a lower total cost. Sensitivity analysis showed that the main results were robust. The main item driving the direct cost in the FMC arm was the cost of drugs. In the case of IS and LMWID, the monitoring and hospital costs were substantially higher due to the different delivery mode, which required a substantial amount of time for each infusion.

It must be noted that little is known about the impact of anemia on health care utilization and costs in general, ${ }^{32-34}$ and economic evaluations amongst comparators are rare in the literature. The results of the current study are in agreement with those reported in a similar one undertaken from a health care payer's perspective in Switzerland. In this study, it was found that treating patients with iron deficiency anemia with FMC instead of IS reduced the cost per treatment cycle by $35 \%$ in patients with inflammatory bowel disease (empirical dose $1000 \mathrm{mg}$ of iron) and by $33 \%$ in patients with gynecological indications (empirical dose $500 \mathrm{mg}$ of iron). ${ }^{35} \mathrm{In}$ another study, the aim was to evaluate the health care costs of IS and FMC treatment in patients with inflammatory bowel disease in an outpatient setting. The study concluded that FCM represents a cost-effective choice in Denmark. ${ }^{36}$ Furthermore, it has been argued that FCM reduces waiting time and waiting list pressure, and also reduces consumables and hospital transport costs. ${ }^{37}$ Similar conclusions were obtained in a study undertaken in Spain, where in a population with preoperative anemia treatment the total cost of
FMC was estimated at $€ 244$ versus $€ 307$ for IS. ${ }^{38} \mathrm{~A}$ recent study undertaken in the UK on outpatients has found that FCM represents a cost-saving option compared to IS but it is more costly than LMWID. ${ }^{24}$ However, this difference may be attributed to the different methodologies, assumptions and unit price data utilized in the two studies, in order to reflect local practice properly.

The analysis pursued suffers from drawbacks and limitations, which are common in studies using similar methodologies. It does not represent experimental research, but instead it is based on an economic model using data reported in the literature, and on various assumptions, and thus it may suffer from biases. In order to limit possible sources of bias, standard recommendations were followed. Thus, a systematic review and assessment of the evidence was performed and stochastic analysis was used to deal with uncertainty. This methodology cannot substitute for real-ife comparisons; however the present model represents a reasonable alternative approach and its assumptions are based on data from published studies in the literature and medical practice and are easy to handle. The results must also be considered in the Greek setting only and on the basis of current resources and drug prices. If any of the underlying parameters change, so may the results and the conclusions of the analysis. Finally, we confined the analysis to the health care and patient perspective and not to society overall. A broader analysis could be the scope of additional research in the future.

\section{Conclusion}

In Greece, health care and pharmaceutical budgets are being cut, disposable income is shrinking, and at the same time unemployment is increasing. Thus, we undertook an 
economic evaluation comparing alternative therapies for anemia management. Ferric carboxymaltose may represent a cost-saving option compared with the other likely alternative existing therapies used for the management of anemia in the National Health Service of Greece at present.

\section{Acknowledgments/disclosure}

The study was funded by Vifor International. The authors report no conflicts of interest in this work.

\section{References}

1. Liu K, Kaffes AJ. Iron deficiency anaemia: a review of diagnosis, investigation and management. Eur J Gastroenterol Hepatol. 2012;24(2): 109-116.

2. Goddard AF, James MW, McIntyre AS, Scott BB. Guidelines for the management of iron deficiency anaemia. Gut. 2011;60(10):1309-1316.

3. Goonewardene M, Shehata M. Anaemia in pregnancy. Best Pract Res Clin Obstet Gynaecol. 2012;26(1):3-24.

4. Kent AJ, Blackwell VJ, Travis SP. What is the optimal treatment for anemia in inflammatory bowel disease? Curr Drug Deliv. October 21, 2011. [Epub ahead of print.]

5. Cavill I, Auerbach M, Bailie GR, et al. Iron and the anaemia of chronic disease: a review and strategic recommendations. Curr Med Res Opin. 2006;22(4):731-737.

6. Pasricha SR. Should we screen for iron deficiency anaemia? A review of the evidence and recent recommendations. Pathology. 2012;44(2):139-147.

7. Locatelli F, Pisoni RL, Combe C, et al. Anaemia in haemodialysis patients of five European countries: association with morbidity and mortality in the Dialysis Outcomes and Practice Patterns Study (DOPPS). Nephrol Dial Transplant. 2004;19(1):121-132.

8. de Benoist B, McLean E, Egli I, et al. Worldwide prevalence of anaemia 1993-2005: WHO Global Database. Geneva: World Health Organization;2008. Available from: http://whqlibdoc.who.int/ publications/2008/9789241596657_eng.pdf. Accessed March, 82012.

9. Marantidou O, Loukopoulou L, Zervou E, et al. Factors that motivate and hinder blood donation in Greece. Transfus Med. 2007;17(6):443-450.

10. Kanavos P, Yfantopoulos J, Vandoros C, Politis C. The economics of blood: gift of life or a commodity? Int J Technol Assess Health Care. 2006;22(3):338-343.

11. Crichton R, Danielson BG, Geisser P. Iron Therapy with Special Emphasis on Intravenous Administration. 4th ed. London, UK: International Medical Publishers; 2008.

12. Kulnigg S, Stoinov S, Simanenkov V, et al. A novel intravenous iron formulation for treatment of anemia in inflammatory bowel disease the ferric carboxymaltose (FERINJECT) randomized controlled trial. Am J Gastroenterol. 2008;103(5):1182-1192.

13. Gordon SS, Hadley PE, Van Wyck DB, et al. Iron carboxymaltose, a new intravenous iron agent for iron deficiency anemia in heavy uterine bleeding Obstet Gynecol. 2007;109(Suppl 4):108S.

14. Qunibi WY, Martinez C, Smith M, et al. Efficacy and safety of IV ferric carboxymaltose (FCM) compared to oral iron in anemic patients with non-dialysis-dependent CKD. 45th Congress of the European Renal Association and the European Dialysis and Transplant Association. Stockholm; 2008.

15. Schaefer RM, Khasabov NN, Todorov NG, et al. The efficacy and safety of intravenous ferric carboxymaltose compared to iron sucrose in haemodialysis patients with iron deficiency anaemia Paper presented at: 45th Congress of the European Renal Association and the European Dialysis and Transplant Association. Stockholm; 2008.

16. Breymann C, Gliga F, Bejenariu C, Strizhova N. Comparative efficacy and safety of intravenous ferric carboxymaltose in the treatment of postpartum iron deficiency anemia. Int J Gynaecol Obstet. 2008; 101(1):67-73.
17. Van Wyck DB, Martens MG, Seid MH, Baker JB, Mangione A. Intravenous ferric carboxymaltose compared with oral iron in the treatment of postpartum anemia: a randomized controlled trial. Obstet Gynecol. 2007;110(2 Pt 1):267-278.

18. Seid MH, Derman RJ, Baker JB, Banach W, Goldberg C, Rogers R. Ferric carboxymaltose injection in the treatment of postpartum iron deficiency anemia: a randomized controlled clinical trial. Am J Obstet Gynecol. 2008;199(4):435. e1-e7.

19. Moore RA, Gaskell H, Rose P, Allan J. Meta-analysis of efficacy and safety of intravenous ferric carboxymaltose (Ferinject) from clinical trial reports and published trial data. BMC Blood Disord. 2011;11:4.

20. Ministry of Health and Social Solidarity [homepage on the Internet]. 2012. Available from: http://www.yyka.gov.gr. Accessed December 17, 2011.

21. Vifor France SA. Ferinject Summary of Product Characteristics. 2009; http://www.medicines.org.uk/EMC/medicine/24167/SPC/Ferinject+ (ferric+carboxymaltose). Accessed September 15, 2011.

22. Vifor (International) Inc. Venofer (iron sucrose injection USP) http://www.medicines.org.uk/EMC/medicine/24168/SPC/Venofer+ (iron+sucrose)/. Accessed September 15, 2011.

23. Pharmacosmos A/S. Cosmofer Summary of Product Characteristics. 2010; http://www.medicines.org.uk/emc/medicine/14139/SPC/ CosmosFer/. Accessed September 15, 2011.

24. Bhandari S. A hospital-based cost minimization study of the potential financial impact on the UK health care system of introduction of iron isomaltoside 1000. Ther Clin Risk Manag. 2011;7:103-113.

25. Lyseng-Williamson KA, Keating GM. Ferric carboxymaltose: a review of its use in iron-deficiency anaemia. Drugs. 2009;69(6):739-756.

26. Hellenic Statistical Authority. Available from: http://www.statistics.gr. Accessed September 15, 2011.

27. Auerbach $\mathrm{M}$, Winchester J, Wahab A, et al. A randomized trial of three iron dextran infusion methods for anemia in EPO-treated dialysis patients. Am J Kidney Dis. 1998;31(1):81-86.

28. Auerbach M, Pappadakis JA, Bahrain H, Auerbach SA, Ballard H, Dahl NV. Safety and efficacy of rapidly administered (one hour) one gram of low molecular weight iron dextran (INFeD) for the treatment of iron deficient anemia. Am J Hematol. 2011;86(10):860-862.

29. Maniadakis N, Fragoulakis V, Pectasides D, Fountzilas G. XELOX versus FOLFOX6 as an adjuvant treatment in colorectal cancer: an economic analysis. Curr Med Res Opin. 2009;25(3):797-805.

30. National Institute for Health and Clinical Excellence, June 2008, available from: http://www.nice.org.uk/media/B52/A7/ TAMethodsGuideUpdatedJune2008.pdf. Guide to the Methods of Technology Appraisal. Accessed March 12, 2011.

31. Willan AR. Statistical analysis of cost-effectiveness data from randomized clinical trials. Expert Rev Pharmacoecon Outcomes Res. 2006;6(3):337-346.

32. Nissenson AR, Wade S, Goodnough T, Knight K, Dubois RW. Economic burden of anemia in an insured population. J Manag Care Pharm. 2005;11(7):565-574.

33. Lyman GH, Berndt ER, Kallich JD, et al. The economic burden of anemia in cancer patients receiving chemotherapy. Value Health. 2005;8(2):149-156.

34. Ershler WB, Chen K, Reyes EB, Dubois R. Economic burden of patients with anemia in selected diseases. Value Health. 2005;8(6):629-638.

35. Brock E, Braunhofer P, Troxler J. Real-life budget impact (BI) of parenteral iron treatment of iron deficiency in Switzerland. ISPOR 13th Annual European Congress November 9 2010; Prague - Poster No PSY12.

36. Bager P, Dahlerup JF. The health care cost of intravenous iron treatment in IBD patients depends on the economic evaluation perspective. $J$ Crohns Colitis. 2010;4(4):427-430.

37. Pugh-Clarke K, Cooper L, Turner J, Fermin J. An evidence-based approach to anaemia management in predialysis chronic kidney disease. J Ren Care. 2009;35 Suppl 2:29-31.

38. Garcia-Erce JA, Diez-Lobo AI, Munoz M. A multicentre comparative study on the efficacy of intravenous ferric carboxymaltose and iron sucrose for correcting preoperative anaemia in patients undergoing major elective surgery. Br J Anaesth. 2011;107(3):477-478. 


\section{Publish your work in this journal}

ClinicoEconomics \& Outcomes Research is an international, peerreviewed open-access journal focusing on Health Technology Assessment, Pharmacoeconomics and Outcomes Research in the areas of diagnosis, medical devices, and clinical, surgical and pharmacological intervention. The economic impact of health policy and health systems

organization also constitute important areas of coverage. The manuscript management system is completely online and includes a very quick and fair peer-review system, which is all easy to use. Visit http://www.dovepress.com/testimonials.php to read real quotes from published authors.

Submit your manuscript here: http://www.dovepress.com/clinicoeconomics-and-outcomes-research-journal 